\title{
Risk Assessment of Two Care Bed Structures in lateral Rollover Tasks
}

\author{
Wang Qi (Wangq@sdju.edu.cn) ${ }^{1}$, Zhou Zhiyong(Zhouzy@sdju.edu.cn) ${ }^{1}$ \\ ${ }^{1}$ Department of Art and Design, Shanghai Dianji University of China, Shanghai
}

\begin{abstract}
Pressure and distortion imposed by automatic care beds can lead to negative effects during interaction process. Motion discrepancy between human body and care bed surface causes shear as another type of risks. While relationship between structure design and risk remains unclear. To quantify design limitation and predict the feasibility of Automatic Care Bed(ACB) in lateral turning over Tasks, a virtual man-bed system was established according to two types of structures. A mannequin was modified to simulate patients of different types of figure. Eighteen subjects ( 6 males and 12 females) were measured by a pressure mapping system for interaction data collection. Distortion, pressure and friction caused by motion discrepancies were quantified to assessed the negative effect of existing structures of care beds. Possibility of structure redesigned is recommended to reduce pressure and distortion. Some auxiliary structures are used to relieve shear and friction.
\end{abstract}

Keywords: Care beds, Patient repositioning, Turning over,Ulcer, Journal of the Ergonomics Society of Korea

\section{Introduction}

Automatic care bed(ACB) has been a solution to the heavy burden of family members and nurses during home care. According to US Agency for health Care Policy and Research, bedridden patients must be repositioned regularly. Pressure ulcers develop when capillaries supplying the skin and subcutaneous tissues are compressed enough to impede perfusion, leading ultimately to tissue necrosis.

Theoretically, ACB can offer such regular assistance and frequent repositions will prevent ulcer. While during the repeated motion process, external forces provided by $\mathrm{ACB}$ may keep the patients in unexpected man-bed interactions and migration. Guide lines and recommendations for bed bound patients on traditional beds couldn' $t$ cover the complex functions of ACB for many reasons. Compression and distortion during or after work cycle are main reasons. Breathe and digestion function may be influenced.. Migration and lack of posture adjustment capability will amplify the effect of friction and distortion. Last, mattress or clothes may be wrapped and cause uncomfortable feeling in repeated work cycle.

As a most frequently adopted function, sitting up is not recommended to be used together with turning over for following reasons: Patient migration resulted in lower torso angles, for $30^{\circ}$ and $45^{\circ}$ of backrest articulations. A migration of $10 \mathrm{~cm}$ resulted in a loss of $9.1^{\circ}$ and $13.0^{\circ}$ of torso angle for backrest articulations of $30^{\circ}$ and $45.0^{\circ}$ respectively(Neal Wiggermann2014). On the other side, turning over to one side will cause torso rotation too. A compound effect of sitting up and turning over will amplify torso angle.

Sitting up is more important in most of situations. For example, positioning the backrest at or above 30 degrees is intended to reduce the risk of ventilator-associated pneumonia because torso elevation decreases the risk of aspirating gastric contents into the lungs. For ulcer patients, it is recommended to reposition body at least every two hours. For example, after lying on your back for a while, turn to your side is necessary. Turning over is also necessary for cleaning.

The goal of the present study was to explore the effect of turning over. Two ACB prototypes are designed to offer new functions including lateral angle adjustment, even 
totally rollover. Widely adopted functions such as back angle adjustment are kept as preconditions.

\section{Method}

To compare the effect of the two solutions, 18 subjects (6 males and 12 females) experienced the sitting up function of type1,with legs lifted together. The process was measured by a pressure mapping system which reflected surface compression distribution slightly concentrated to buttock and thigh in both situations.

Migration and obvious surface pressure concentration to buttock and thigh was found by 12 and 14 subjects respectively when backrest has an articulations of $30^{\circ}$. That caused two negative effects: 1.Different axes between upper and lower parts of body.2.Body migration. Both effects make man-bed interface unpredictable and make repeated turning over hard to predict.So effect of turning over is limited to to be incompatible with backrest articulation.

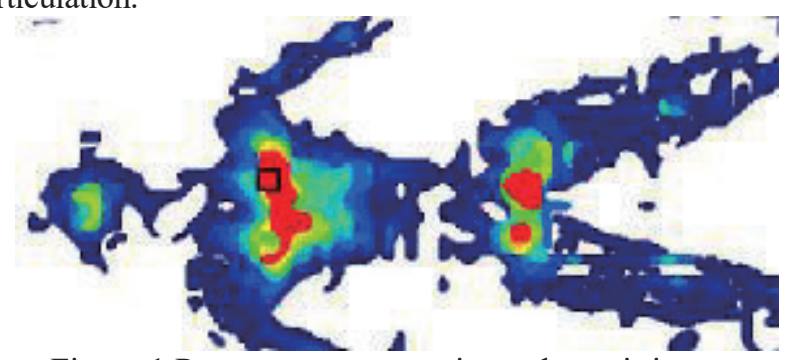

Figure.1.Pressure concentration when sitting up

First type of automatic care bed is shown in Fig.1.It' $\mathrm{s}$ bed boards are divided into 4 main parts from head to feet. The first part behind back includes left part and right side. They can rotate together to work as back rest. When one of them rotates around the symmetry axis, the patient is expected to turn over laterally. Each bed board is covered by a fixed mattress of $3 \mathrm{~cm}$.

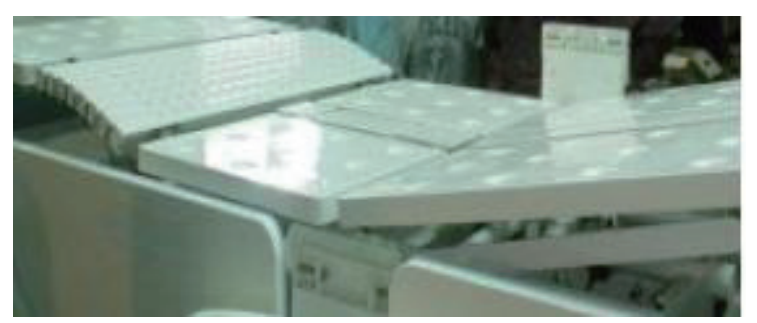

Figure 2. Bed boards and coordinate of type 1 .

In turning over experiment, the subjects lie in the symmetrical axis, pushed by the right board to turn left until a bed board angle of $45^{\circ}$. Then go on increasing rotation angle to realize a total rollover. Each process was repeated three times.A subjective questionnaire was use to record the results. Six subjects finally didn' t finish the process because they were simply pushed to the left. Another four subjects also experienced the situation once or twice.

Though, limited by sample size and questionnaire accuracy. It is easy to find that the process is highly unpredictable.Shortcomings viewed as acceptable include: The patients can' t be returned to their original position. Possible soft tissue compression and shear caused by large angle adjustment. Bad feeling caused by friction on back and head had been reflected by all subjects. Requirements of long term patients remain unknown.

Type 2 is an improved version to relieve the pressure on back. It' $\mathrm{s}$ simulated basing on a mannequin provided by HUMANCAD 2.0.

As Fig. 3 shows, the board in the middle can rotate around two different axes. When it turns right side, the middle board have the edge of right board as rotation axis. One motor drive two V shaped rods to rotate clockwise and push the middle board to rotate around the edge of right board. The near part of right board is also pushed upward to hold head.

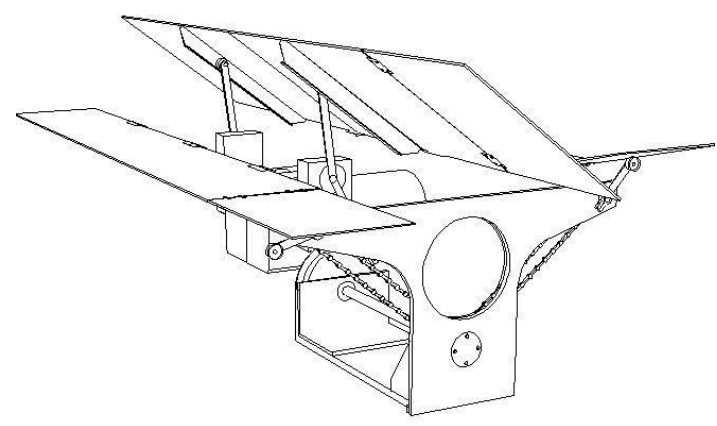

Figure 3. Bed boards and structure of type 2 .

Such a design can theoretically reduce the discrepancy between back and board in lateral rotation task at the cost of leaving head of patient unsettled. A head support structure is driven by the same motor, it pushes a board under head position upward. Both the middle board and supporting part provide self-locking function.

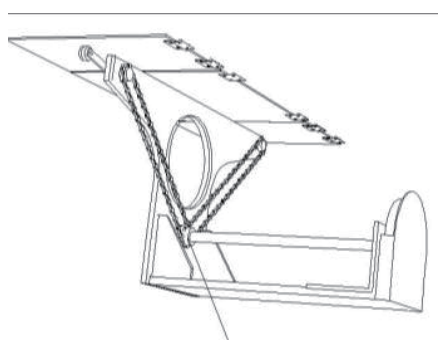


Figure 4. Head support structure of type 2.
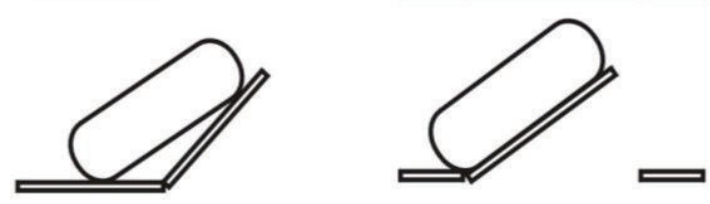

Figure 5. Structure comparison between two ACBs

External strain still exist because of the dimension and shape difference between thoracic cavity and pelvis. Some more structure should be provided to keep their relative positions, but even such a structure can not promise a suitable pelvic posture.

It's impossible to use pressure mat in turning over measurement because of complex path and unavoidable displacement.But estimation of both types during motion cycle could be simulated to some extend by a mannequin. A dimension setting provided by China national standard was used to define the mannequin. The mannequin reflects anthropometric parameters and figure type. while it can't reflect deformation of soft tissue caused by compression. As the largest cross section, two types of shoulder shape are shown in Fig4. The flat shaped shoulder has a longer arm, the round shaped shoulder has a larger friction surface.
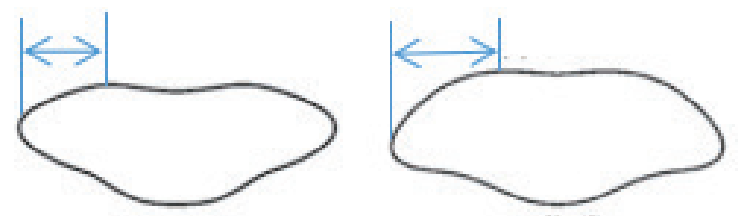

Figure 6. Different shoulder cross section shape and friction distance in type 1

When shape of shoulder cross sections in Fig.6 are simplified to to be a flat type and a round type. Straight line shaped type is theoretically inclined to be pushed to left side while the round type is more inclined to rotate when pushed by ACB type 1 .

Effects of two types of ACBs are listed in Table1:

Table1. Effect comparison of two types of ACB

\begin{tabular}{|l|l|l|}
\hline & Type1 & Type2 \\
\hline Compressed & Back side of & One shoulder \\
\hline
\end{tabular}

\begin{tabular}{|c|c|c|}
\hline positions & $\begin{array}{l}\text { shoulders, } \\
\text { head, } \\
\text { buttocks }\end{array}$ & \\
\hline $\begin{array}{l}\text { Motion } \\
\text { discrepancy } \\
\text { positions } \\
\end{array}$ & $\begin{array}{l}\text { Back,buttock, } \\
\text { head and thigh }\end{array}$ & $\begin{array}{l}\text { Head and } \\
\text { low lumbar } \\
\text { part }\end{array}$ \\
\hline $\begin{array}{l}\text { Twist } \\
\text { potential and } \\
\text { position }\end{array}$ & $\begin{array}{l}\text { Low lumbar } \\
\text { and pelvic }\end{array}$ & $\begin{array}{l}\text { Low lumbar } \\
\text { and pelvic }\end{array}$ \\
\hline $\begin{array}{l}\text { Side effect of } \\
\text { work cycle }\end{array}$ & $\begin{array}{l}\text { Unpredictable } \\
\text { migration in } \\
\text { both directions }\end{array}$ & $\begin{array}{l}\text { Predictable in } \\
\text { head-to-bed } \\
\text { direction }\end{array}$ \\
\hline $\begin{array}{l}\text { Friction } \\
\text { surface }\end{array}$ & $\begin{array}{l}\text { Back area } \\
\text { Partly Shown } \\
\text { in Fig.6 }\end{array}$ & Left shoulder \\
\hline $\begin{array}{l}\text { Distance of } \\
\text { shear or } \\
\text { friction }\end{array}$ & $\begin{array}{l}\text { Shown in Fig. } \\
6\end{array}$ & Negligible \\
\hline $\begin{array}{l}\text { Compression } \\
\text { on friction } \\
\text { surface during } \\
\text { rotation }\end{array}$ & $\begin{array}{l}\text { Obvious on } \\
\text { both scapula } \\
\text { positions }\end{array}$ & $\begin{array}{l}\text { No more than } \\
\text { rollover in flat } \\
\text { bed }\end{array}$ \\
\hline $\begin{array}{l}\text { Effect on } \\
\text { head }\end{array}$ & Friction & $\begin{array}{l}\text { Suspension but } \\
\text { solved }\end{array}$ \\
\hline $\begin{array}{l}\text { Side effect on } \\
\text { trunk }\end{array}$ & $\begin{array}{l}\text { Twist, shear } \\
\text { and larger } \\
\text { surface } \\
\text { compression }\end{array}$ & $\begin{array}{l}\text { Twist, shear } \\
\text { and } \\
\text { compression, }\end{array}$ \\
\hline
\end{tabular}

\section{Results}

Type 1 is not a suitable solution for health care at home because space for thorax and pelvic is reduced during rotation. The squeezing motion is uncomfortable or unbearable. It's hard for manual help to avoid this effect.

Type 2 partly solved squeezing problem of type 1 . While inclination of twist remains when turning over. More than one work rotation may have clothes crumpled. After one work cycle the patient can't return to symmetry axis without reposition. In spite of all upper shortcomings, it's still a reasonable solution for frequently turned over situations so far. But further study is necessary, which requires a controlled laboratory environment.This assessment provides a precondition for minimizing migration, cumulative 
movement, and torso compression.

Although shear and friction were not directly measured in this study, it is logical that a repetitive movement across the mattress may increase the risk over time. Both types can' t avoid lateral migration and twist in pelvic position.

Benefit of both types is the potential to limit manual lifting and patient-handling tasks, which are known causes of injuries and musculoskeletal disorders in nurses and other health care workers. The injuries sustained by health care workers have been reported as often life-altering and career-ending.

\section{Conclusion}

Bed design significantly impacts the amount of migration and local friction during turning over tasks. Migration, cumulative movement and torso compression were higher on beds lack the ability to provide suitable space and path for body parts. Increased migration and friction may increase the risk and uncomfortable feelings of patients, also increase the risk of low back injuries for caregivers. Torso compression may impact patient comfort.

Effect of ACB rotation should be accompanied by structure improvement to avoid soft tissue compression, shear twist and migration. As a practical method, to assess the movement of the Acromion and change in distance between the shoulders, rotation center and the trochanter (to estimate torso compression). Local pressure mapping should be utilized as a tool to assess effect of shear and the pressure on shoulder.

\section{Acknowledgements}

The authors thank Shao-Jie Xin, Ting-Jun Wang for their technical assistance. The research is supported by Academic Discipline Project of Shanghai Municipal Education Commision (project number J51902) .
Wiggermann N1, Kotowski S, Davis K, VanGilder C., I., The effect of patient migration in bed on torso elevation., Nurs. Res. May-Jun;64(3):221-5.2015.

Clark M., Repositioning to Prevent Pressure sores-what is the evidence? Nues Standard ;13:58-60.1998.

Ayer J.K.. Bouten CV., Oomens CW. , Baaijens FP. , Bader DL., The etiology of pressure ulcers:skin deep or muscle bound? Arch Phys Med Rehabil 84:616-619,2003.

Salzberg CA., Byrne DW., Cayten CG.,vanNiewerburgh P., Murphy JG., M. Viehbeck, A new pressure ulcer risk assessment scale for individuals with spinal cord injury. Am J Med Rehabil 75:96-104,1996.

Stobee T.J., Plummer R.W., Jensen R.C., Attfield M.D., Incidence of low back injuries among nursing personel as a function of patient lifting frenquency.Journal of safety research, 19,21-28,1988.

Ankrom M., Bennet R,Sprigle S, ,et al.Pressure-related deep tissue injury under intact skin and current pressure ulcer staging Systems. Adv skin wound care 18(1):35-42.2005.

Makhsous M.,Lin F., Hendrix, R.W. Hepler, M., Zhang L.Q., Sitting with adjuatable ischial and back supports: Biomechanical changes. Spine 28, 1113-1121.2003.

Won, A., Lapane, K. L., Vallow, S., Schein, J., Morris, J. N., \& Lipsitz, L. A.Long-term effects of analgesics in a population of elderly nursing home, residents with persistent nonmalignant pain. Journals of Gerontology -Series A, Biological Sciences and Medical Sciences, 61(2), 165-169.2006.

Voz, A., Williams, C., \& Wilson, M. Who is turning the patients? A survey study, Journal of Wound Ostomy Continence Nursing, 38(4), 413-418. 2011.

Wywialowski, E. F. Tissue perfusion as a key underlying concept of pressure ulcer development and treatment. Jorunal of Vascular Nursing, 17(1), 12-16.1999.

Young, T. . The 30 degree tilt position vs the 90 degree lateral and supine positions in reducing the incidence of non-blanching erythema in a hospital inpatient population: a randomised controlled trial. Journal of tissue viability, 14(3), 88, 90, 92-96.2004.

Zhang, Q., Lindberg, L-G., Kadefors R., Styf, J. A non-invasice measure of changes in blood flow in the human anterior tibial muscle. European Journal of Applied Physiology, 84, 448-452.(2001).

\section{References}

